\title{
The Impact of Servicescape Perception on Perceived E-Commerce Value
}

$$
\text { and Client Loyalty }
$$

\author{
Jeffri Prayitno Bangkit Saputra ${ }^{1, *}$ \\ ${ }^{1}$ Department Information System, Universitas Amikom Purwokerto, Indonesia \\ ${ }^{1}$ prayitnojeffry@amikompurwokerto.ac.id*; \\ * corresponding author
}

(Received: August 8, 2021; Revised: August 22, 2021; Accepted: October 12, 2021; Available online: December 1, 2021)

\begin{abstract}
While previous research on e-servicescapes has focused on the ordinary Internet user, several studies show that heavy Internet users are the target audience. To maximize firm profitability, it is vital to understand the nature of heavy user consumption; hence, this study examines the primary components of e-servicescapes and their relationship to buy intent using moderated data from heavy and light Internet users. Three hundred and forty-two genuine internet users with online purchasing experience answered an online questionnaire, and discrepancies were determined using structural equation modeling. For ordinary users, aesthetic appeal and interaction are significant factors in purchase intention; for heavy users, interactivity is the most important attribute, followed by aesthetic appeal, layout, and functionality; and for light users, aesthetic appeal is the sole consideration. Additionally, our data show that financial stability does not help heavy, regular, or light users. We demonstrate how heavy and light Internet users evaluate e-servicescapes to signal quality attributes and contribute to their cognitive responses and purchase intentions based on their consumption traits by integrating purchase intentions with e-service quality and segmentation theory in e-servicescapes. It is advised that online merchants identify heavy and light users, rethink their current e-servicescapes, and apply more tailored marketing methods to attract and retain heavy and light users, as well as increase their purchase intent. While this study concentrated on the most salient characteristics of heavy users, more research is required to explicate additional critical mediators. This poll makes no mention of the three kinds of websites or product qualities. Finally, demographic and psychological variables such as gender and personal characteristics may act as significant mediators in the link between the e-servicescape and purchase intention, but their relevance requires more research.
\end{abstract}

Keywords: E-Servicescape; Online Marketing, E-Commerce

\section{Introduction}

The consumer considers the cumulative influence of all discrete stimuli offered by the physical environment throughout the service encounter and hence responds to the environment holistically. The surrounding environment was dubbed the "servicescape" in a previous study, and it was argued that managers might give consumers an excellent shopping experience by creating an unbelievable servicescape, hence enhancing their purchase-related intents and behaviors. As a result, the servicescape is an integral part of research on service quality management. Numerous research on the servicescape in the online purchasing environment have been undertaken as a result of the growth of e-rapid commerce. Due to the fact that buying behaviors differ across online and brick-and-mortar enterprises, the e-servicescape has been demonstrated to have a significant influence on online customer behavior in the literature on electronic service quality. The empirical evidence available to date indicates that e-servicescape combines Bitner [1] and Harris and Goode [2] definitions of "the design of the online environment and the quality of service staff that defines the context that elicits internal reactions from the lead customer with the view approach." or avoidance behavior is associated with purchase intention, emphasizing the critical role of the e-servicescape in stimulating e-commerce. While the majority of previous research on the e-servicescape has concentrated on it as a first-order construct, some researchers have demonstrated that this categorisation is insufficient and have begun to analyze other dimensions or sub-dimensions.

Despite universal agreement in current research that a more comprehensive explanation may be reached through the use of second-order variables, relatively few studies have studied e-servicescapes and their possible implications for purchase intention in this way. Various studies have evaluated a subset of the e-servicescape, called "website beauty," 
by analyzing its influence on purchase intention using a second-order construct, but none have examined the entire e-servicescape. This knowledge gap is predictable, considering the discipline of Internet retail management's relatively young. Nonetheless, the dearth of study on the characteristics that shape the e-servicescape and their influence on purchase intention reveals that internet merchants lack knowledge about online consumer behavior that may benefit them in attracting and retaining clients.

Wu et al. [3] hypothesized that gender and past online buying experience would serve as critical moderating variables in helping us better grasp the e-servicescape and its influence on purchase intention. They hypothesized, more particularly, that male/experienced and female/inexperienced consumers would exhibit unique consuming habits, acting as a moderator for the link between the e-servicescape and purchase intention. While they highlighted the potential for consumption characteristics to serve as moderators, more research is necessary to ascertain how consumption variables alter e-servicescapes and purchase inclinations.

Consumption considerations usually include lifestyle or demographic characteristics, with volume segmentation playing a crucial role. Twedt [4] categorizes consumers as heavy or light users depending on their purchasing power. Subsequent study has thrown more insight on the decision-making processes of heavy and light users, with heavy users displaying superior product knowledge and expertise and placing a larger emphasis on "relevant information," "financial security," and "information privacy" than light users. Additionally, heavy users scrutinize web designs more closely and may place a higher premium on "aesthetic appeal" than light users do. While earlier study suggested that heavy and light users prioritized distinct page features, this hypothesis has not been validated in reality [5]. As a result, the research question that follows is posed: Does the desire for distinct or similar website features by heavy and light users affect the link between the e-servicescape and purchase intention? Which dimension or sub-dimension is regulated when the attention is shifted?

In the realm of e-commerce, the majority of purchase decisions are made by regular Internet users. Under the assumption of similar consumer consumption, identical evaluative characteristics were applied, resulting in equivalent cognitive reactions. Nonetheless, because heavy and light Internet users place different values on various website aspects and their evaluative characteristics for e-servicescapes are very varied, their emotional reactions and behavioral intents are controlled [6]. Again, this premise is not supported by actual evidence and warrants additional investigation. By addressing research gaps about the expected moderation of the e-servicescape by heavy and light users, as well as their impact on buy intention, we believe that Internet merchants will be able to offer more complete marketing tactics to a varied set of Internet customers.

To provide a more full picture of how users perceive the online environment, we asked seasoned Internet users who had just completed an online purchase [7]. Additionally, one study argues that heavy users are primary consumers, emphasizing the importance of understanding their consumption behaviors. By concentrating on heavy users, we may concentrate the study's focus on the most crucial features of the e-servicescape and gain a more detailed understanding of how the e-servicescape influences purchase intention [8].

To advance our understanding of the e-servicescape and purchase intention, we integrate and apply e-service quality and segmentation theory, elucidating how heavy and light users perceive and contribute cognitive reactions and intentions to the e-servicescape characteristics. Purchases should be diverse in nature to represent the diversity of consumption. By bridging some research gaps, we add to the body of knowledge. To begin, we build a new interaction level and a 2nd notion for e-servicescape in order to explore the link between both the e-servicescape and purchase intention. Second, we use e-service qualities and categorization theories to the e-servicescape model in order to identify contextual variables (i.e. consumer nature) that influence the e-servicescape and purchase intention. Lastly, we identify the most crucial components of the e-most servicescape by interviewing the most significant study participants (heavy users). 


\section{Hypothesis Development and Literature Review}

The scientists constructed and evaluated a complete theoretical model that accounts for the interaction between the e-servicescape and buy intent, as well as the unique consumption habits of heavy and light users with related moderating effect on their behavioral intentions.

\subsection{Purchase intention antecedents}

Purchase intention is often defined as the likelihood of a consumer purchasing a specific product. A higher purchase intention indicates that the consumer is more inclined to acquire the things. Purchase intention is used by marketers to forecast long-term purchasing behavior since it is seen as a critical sign of continuing purchasing. Purchase intention is influenced by a variety of variables, including perceived price, perceived risk, and contextual variables such as the opinions of others. With the advent of e-commerce, the idea of buy intention was extended to the online realm, and various research urged for its inclusion. For example, Zeithaml et al. [9] proposed a relationship between e-service quality (i.e., ease of use, security, design, and compliance) and purchase intention, positing that Internet consumers experience Web sites, evaluate their e-service quality, contribute to perceived value, and thus shape their purchase intentions. Thus, it is vital to understand how Internet users are motivated to make a purchase, how they obtain critical information through personal experience and contextual conditions, and how they evaluate and compare various prospective goods before making an online purchase.

\subsection{Composition of the e-servicescape and its effects on purchase intention}

The word "servicescape" was invented by Baker [10], and Bitner [1] operationalized and defined it afterwards. Recently, the concept of servicescapes has been widely applied in a variety of studies on service quality, as it has been demonstrated that servicescapes influence consumers' emotions and behavior, promote cognitive, emotional, and physical responses, and facilitate the formation of cognitive judgments and beliefs that result in specific behaviors. While e-commerce continues to grow in popularity, the servicescape concept has been extended to the online environment, with numerous researchers examining the effects of online servicescape variables such as website design, online store atmosphere, and financial security on online shopping behavior.

The term e-servicescape is derived from the terms cyber marketscape and e-scape. Numerous studies have suggested that e-servicescapes are distinct from servicescapes; for example, Hopkin et al. [10] use the previously mentioned dimensions of servicescape to propose that an e-servicescape consists of "ambient conditions," "spatial layout and functionality," and "signs, symbols, and artifacts," and discusses the effects of e-servicescape on related attitudes. website, appraisal, and intention to purchase. Harris and Goode [2] continue to describe e-servicescape as "factors in the online environment that exist during service delivery," categorizing them as "aesthetic appeal," "layout and functionality," and "financial security." The apparent aesthetic presentation, design distinctiveness, and entertainment of a website all contribute to its aesthetic appeal. The function and appearance of the site are assessed based on its usability, informational relevance, degree of customization, and engagement, while financial security is decided by transaction efficiency and perceived risks. Tran et al. [11] divide the aesthetic appeal dimension into two sub-dimensions (visual appeal and entertainment value), the layout and functionality dimension into three sub-dimensions (interactivity, usability, and flexibility), and the financial security dimension into two sub-dimensions (ease of payment and perceived security). Meanwhile, Lee and Jeong [12] stated that an e-servicescape should comprise ambient, design, and social dimensions, with ambient factors such as graphics, font size, and overall layout determining the amount to which a website creates a pleasant and cheerful mood among consumers. Additionally, they define social factors as those that may impact how customers engage virtually with internet providers via technology like characters and online support desks. Additionally, Lai et al. [13] argued that the e-servicescape has four dimensions: atmosphere; design; interactivity; and signs, symbols, and artifacts. Categorization, basic settings, and a navigation bar are all included in the design. Ambiance encompasses photographic quality. Interactivity is defined as receiving pricing information and confirmation emails. Signs, symbols, and artifacts, such as business logos. 
Regardless of how the e-servicescape is constructed, many researchers agree that it plays a significant role in influencing consumers' emotions and behavior by prompting cognitive, emotional, and physical responses and thus shaping cognitive judgments and beliefs that result in specific behaviors in the online environment. Due to the difficulty of judging online service settings, consumers see website qualities (i.e., e-servicescapes) as signal quality attributes, which shapes their behavioral intents. For instance, a well-designed website improves consumers' first impressions, encouraging them to trust the site and leading to increased website identification, which raises buy intention. Additionally, security and reliability have an effect on customers' privacy concerns, which has an effect on their purchasing decisions. This study is based on the e-service quality theory, which states that users get familiar with certain features of e-servicescapes websites, identify the most desired service quality qualities within e-servicescapes, and then form behavioral intents. Users will view an e-servicescape positively if it delivers a high-quality online environment; this results in an improvement in the service's quality, prompting a pleasant cognitive reaction that boosts their purchase intention.

H1. Internet users have a favorable association between their e-servicescape and their purchasing intention.

\subsection{Differences in behavior between heavy and light Internet users with regard to the e-servicescape and purchasing intent}

Heavy users play a crucial role in segmentation. Twedt [4] invented the phrase "heavy users," referring to a small percentage of consumers (about 20\%) who consume an inordinate amount (roughly 80\%) of total sales. Heavy consumers often make a substantial profit for the firm due to their high consumption and regularity. Heavy and light users exhibit a variety of behavioral characteristics; for example, heavy users are more engaged with the product and are more eager to try new products as a consequence of their extensive product knowledge and experience; they are also more likely to voice their thoughts.

The extensive usage of the Internet attests to the presence of a significant number of Internet users. Initially, the phrase "heavy Internet user" was expressed in terms of time spent online. Despite the widespread adoption of e-commerce, previous studies denote that usage time, expenditure, purchase volume, and expertise are much more precise indicators of heavy Internet users than time spent online; this study demonstrates that heavy and light Internet users exhibit distinct usage characteristics that affect their motivations successively. Chiou and Pan [14] investigated the moderating effect of heavy and light Internet users on the relationship between satisfaction and loyalty to online bookshops and discovered that price had a stronger impact on satisfaction among light Internet users, whereas trust had a greater impact on loyalty.

According to the segmentation management literature, heavy and light Internet users place a premium on certain website quality criteria that impact their behavioral intentions sequentially. While both heavy and light Internet users encounter and learn about distinct e-servicescape characteristics, the framework hypothesizes that they react in different ways depending on their unique consumption behaviour as well as contribute the favored quality of service of these e-servicescapes to successively form their unique purchase intentions.

H2. Disparities in internet usage between heavy and light users act as a moderator of the relationship between e-servicescape and purchase intention.

The research indicates that e-servicescapes are defined by four primary dimensions: aesthetic attractiveness, layout and functionality, financial stability, and engagement. To begin, the aesthetic appeal of the item is heightened by its uniqueness, visual appeal, and pure entertainment. Music, ambience, site design, and color are all aesthetic elements. Increased visual appeal induces enjoyable and exciting sentiments in Internet consumers, boosting their proclivity to purchase [15]. Based on the categorization research, heavy Internet users tend more than light Internet users to assess a website's design attributes, since heavy users are more used to scrutinizing components of a website which represent the quality of the services. We believe that a more visually appealing website would be seen as a higher-quality service provider, prompting a favorable cognitive response and increasing users' purchase intention.

H2-1. The connection between visual appeal and purchase intention was greater among heavy Internet users than among light Internet users. 
Second, layout and functionality are determined by the simplicity with which information can be retrieved, its relevance, and the extent to which information can be customized and personalized [16]. These factors aid Internet users in more easily navigating websites, which is facilitated by clear information and directions. A well-designed and functional website has the potential to greatly improve user perceptions of the site, resulting in greater purchase intent. Due to the fact that heavy Internet users spend significantly more time online than light Internet users, they value aesthetics and usability. We assume that if heavy users can acquire information quickly, they will view the web to provide a higher level of electronic service than other websites, boosting their tendency to purchase.

$\mathrm{H} 2-2$. The link between layout and functionality and purchase intention was greater among heavy Internet users than among light Internet users.

Thirdly, financial security is defined by payment convenience and perceived security, which refer to how users view the payment process and general policies of a website to be safe or secure [17]. Whenever a website's risk perception is high, it corresponds with increasing feelings of enjoyment and trust, which improves purchasing behavior. Since more time is spent purchasing online by heavy Internet users than by light Internet users, consumers are much more conscious of the dangers. Furthermore, since heavy users conduct more activities than occasional users, they are more worried than light users about Internet security and privacy issues. According to the segmentation literature, if a website provides greater financial protection, we anticipate that heavy users would regard the website's perceived risk and service quality to be higher than those of other websites, resulting in increased purchase intentions.

H2-3. Among heavy Internet users, the relationship between financial stability and purchasing intention was stronger than among light Internet users.

Additionally, interaction is determined by price information and verification emails, that allow customers to quickly purchase items and check their status. Additionally, engagement is a proxy for an Internet retailer's ability to communicate with customers and resolve concerns rapidly [18]. As previously stated, heavy internet users spend a bigger proportion of their time and resources buying online than light internet users. As a result, they demand more information to make purchasing decisions and are more worried than light users about the speed with which problems can be resolved, as heavy users incur higher switching costs when switching websites. We believe that if a website reacts quickly to user interaction, heavy users will view it as being of higher quality and will react positively, leading in a larger purchase intention than light users.

H2-4. Interactivity and intention to purchase were significantly more related with heavy Internet users than with light Internet users.

\section{Research Method}

\subsection{Structure, measures, and statistical methodologies of the research}

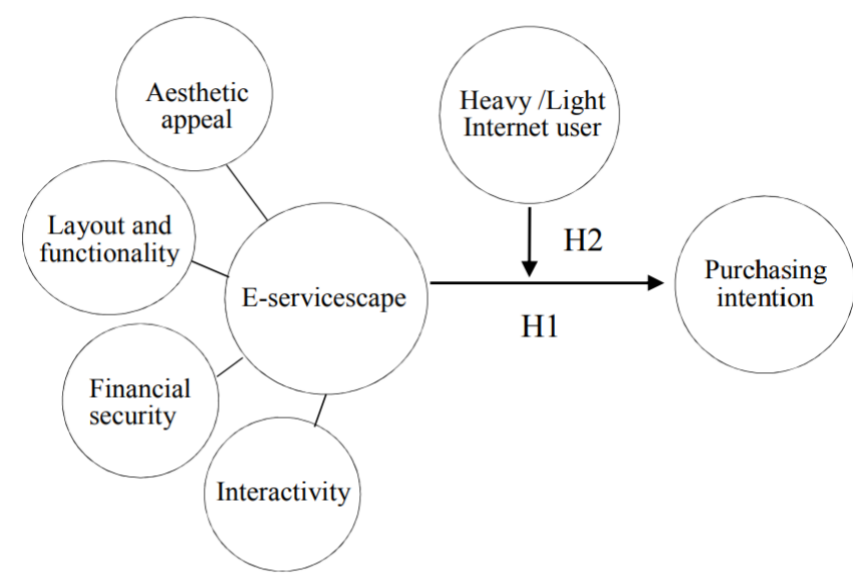

Fig. 1. Research Model 
The suggested conceptual framework for this investigation is depicted in Figure 1. The statistic is intended to measure the moderating effect that heavy and light Internet users may have on the e-services and purchase intention landscapes. To test for a moderating impact, this study initially used general Internet users as a comparison model (i.e., the complete sample served as general users), and then compared general users to heavy and light Internet users consecutively. This study included questionnaires and a seven-point Likert scale.

The e-servicescape was measured using 44 items adapted from those developed by Harris and Goode [2] and Lai et al. [3] items are classified into the following four dimensions: aesthetic appeal, layout and functionality, financial security, and interactivity. Users were classified as heavy or light according to the following five items adapted from Korgaonkar and Wolin [19]: time spent online per day, level of interest in online shopping, frequency of online shopping, online consumption experience, and proportion of monthly income spent on online shopping. Moreover, this criterion is identical to that used by Pleshko and Al-Houti [20]. This research employs cluster analysis to identify respondents as light or heavy users based on these characteristics. Finally, five questions modified from Dodds et al. [21] were used to assess purchase intention.

Initial measurements were taken using a stratified sample technique in a pilot test. Sixty valid replies were gathered in total and tested for reliability and validity. The pilot results indicate that all constructs passed the reliability test with a score greater than 0.7 , and that the factor loading of all items was greater than 0.5 in the confirmatory factor analysis. The trial results validate our progress toward establishing a structured data collection process.

\subsection{Subjects of study and data collecting}

To guarantee that the samples taken are representative of the research subjects, this study employs stratified sampling. The stratified proportions and variables (i.e., gender and age) are taken from the Software market dataset 2018 dataset obtained from Kaggle, which indicates that $62 \%$ of Internet consumers are female, $14.8 \%$ are older than 39 years, $77.2 \%$ are between the ages of 20 and 39 , and $8 \%$ are under the age of 20 . Additionally, this study used Chang and Chen [22] sampling distribution as a second reference, which indicated that $46 \%$ of respondents were female, $10 \%$ were under the age of $20,62 \%$ were between the ages of 20 and 34 , and $21 \%$ were between the ages of 35 and 45 . According to these two sampling distributions, $62 \%$ of respondents in this study are female, $8 \%$ are under the age of $20,63 \%$ are between the ages of 20 and 40 , and $29 \%$ are between the ages of 41 and 65 .

After adjusting for stratification, convenience sampling was used to recruit volunteers who expressed an interest in the research topic. All participants were informed that they would not be rewarded for their time and that the questionnaire would be used exclusively for academic purposes. Because our study's target population was Internet users, data were obtained mostly by online questionnaires; nevertheless, using anonymous online questionnaires dramatically raised answer bias, and online participants could not be monitored or contacted to settle any misunderstandings. To prevent the problem of duplicated sampling via electronically submitted surveys, $60 \%$ of questionnaires were printed and $40 \%$ were submitted online.

The majority of respondents who replied electronically completed the study using Google Forms, free questionnaire websites, or Facebook. The majority of respondents to the printed surveys were accosted on the street or convinced to participate by acquaintances, coworkers, or family members. Prior to the main interview, participants were told to answer all questions based on their most frequently visited online shopping sites in the preceding 12 months. No response rate estimations were made due to the questionnaire's stated objective of identifying generic Internet users (rather than specific individuals). 374 respondents responded to the primary questionnaire. Following the exclusion of invalid samples (those who had not made an online purchase in the prior 12 months), 342 valid questionnaires were retained for analysis; the valid response rate is 91.4 percent.

\subsection{Tests of reliability and validity}

The extracted mean variance, as shown in Table 1 , ranged between 0.41 to 0.58 . Furthermore, the majority of composite reliability values above the 0.7 threshold, passing the convergent and composite validity condition. Cronbach's alpha values for the reliability test were all larger than 0.7 , which is the often used cutoff value in prior studies. 
J. Saputra / IJIIS vol. 4, no. 3, December 2021, pp 216-230

Table. 1. Tests of Reliability and Validity

\begin{tabular}{ccccc}
\hline Variable & Factor & a & AVE & CR \\
\hline
\end{tabular}

Attractiveness

Visual appeal

Astounding sense of

design

Visually appealing

.841

The aesthetics of the

website

Utilization of features

icon

The appearance of the website

\section{Design originality}

The initial version of the website

The design and color

scheme of the website

The design of the

website

Freshness

Difference

Value in terms of entertainment

Entertaining

Excitement

.676

Purchase

Gratification

.574

Setup and operation

Accessible

Consistency

Methods for easily navigating between linked pages and sections

Conduct a keyword search

796

784

508

.687

.644

9

(1)

.923

.5456

.4149

.7384

.8014

.4475 
User-friendly

Information

relevance

Indicate plainly

Visual data that is

easily accessible

Browse with ease 806

A substantial amount

of unnecessary

information

Easily to search

\section{Configurability}

Increased

customizability equals

increased happiness

Personalize the

webpage

Occasionally, use the

right name

Comply with the

requirements

Financial well-being

Payment facilitation

Implement a payment

process

Methods of payment

Compensation for time spent

The procedure for checkout

The specifics of the payment process

Security as seen

Payment process security

The warning about internet purchasing

The notice of online shopping
.5739

.8690

806 
The protected system

The safe method of payment

\section{Interactivity}

The website may be viewed in a variety of ways.

Includes a search function

Assisting in the comparison of items and pricing

Interaction between consumer and website that is dynamic

Online Q\&A answer

\subsection{Common method variance concerns}

Our data were collected using a single survey instrument, which raises broad concerns about methodological bias. Furthermore, we used the Podsakoff and Organ [23] one-factor Harman test, which categorized all 54 variables unequivocally into 10 distinct factors with eigenvalues larger than one, rather than a single component. The 10 parts contributed for 70.33 percent of total variation, whereas the largest single component accounted for $32 \%$, falling short of the required $39 \%$. The findings show that the overall approach is rather impervious to alteration.

\section{Results and Discussion}

\subsection{Analysis of the differences between heavy and light users}

To investigate the differences in e-servicescape attributes among heavy and light Internet users, these research utilised clustering algorithms to classify all Internet users as light or heavy users based on the regularity and monetary value of various online purchases. The following table summarizes the conclusions of a descriptive analysis of Internet users in general, heavy, and light. $58 \%(\mathrm{n}=198)$ and $42 \%(\mathrm{n}=144)$ of 342 respondents were content heavy users. $68 \%$ of heavy users are female, $32 \%$ are male; $73 \%$ are between the ages of 20 and $40,19 \%$ are over 40 , $64 \%$ are undergraduates, and $45 \%$ have a monthly income of between $\$ 2,000$ and $\$ 4,000.58 \%$ of light users were female, $42 \%$ were male, $51 \%$ were between the ages of 20 and $40,45 \%$ were over $40,56 \%$ were undergraduates, and $42 \%$ had monthly salaries between $\$ 2,000$ and $\$ 4,000$.

Table. 2. Internet user attributes

\begin{tabular}{|c|c|c|c|c|c|c|}
\hline & \multicolumn{2}{|c|}{ General Internet user } & \multicolumn{2}{|c|}{ Light Internet user } & \multicolumn{2}{|c|}{ Heavy Internet user } \\
\hline & $\mathrm{N}$ & $\%$ & $\mathrm{~N}$ & $\%$ & $\mathrm{~N}$ & $\%$ \\
\hline \multicolumn{7}{|l|}{ Sex } \\
\hline Man & 124 & 36 & 60 & 42 & 64 & 32 \\
\hline Woman & 218 & 64 & 84 & 58 & 134 & 68 \\
\hline
\end{tabular}


J. Saputra / IJIIS vol. 4, no. 3, December 2021, pp 216-230

\begin{tabular}{|c|c|c|c|c|c|c|}
\hline \multicolumn{7}{|l|}{ Age } \\
\hline$<20$ & 22 & 6 & 6 & 4 & 16 & 8 \\
\hline $20-40$ & 217 & 64 & 73 & 51 & 144 & 73 \\
\hline$>40$ & 103 & 30 & 65 & 45 & 38 & 19 \\
\hline \multicolumn{7}{|l|}{ Marriage } \\
\hline Married & 120 & 35 & 66 & 46 & 54 & 27 \\
\hline Unmarried & 222 & 65 & 78 & 54 & 144 & 73 \\
\hline \multicolumn{7}{|l|}{ Degree } \\
\hline $\begin{array}{l}\text { Junior High } \\
\text { School }\end{array}$ & 6 & 3 & 5 & 4 & 2 & 1 \\
\hline $\begin{array}{l}\text { Senior High } \\
\text { School }\end{array}$ & 39 & 12 & 16 & 11 & 24 & 13 \\
\hline Specialist & 57 & 17 & 34 & 24 & 24 & 13 \\
\hline $\begin{array}{l}\text { Undergraduat } \\
\text { es }\end{array}$ & 207 & 61 & 81 & 57 & 127 & 65 \\
\hline $\begin{array}{l}\text { Master or } \\
\text { above }\end{array}$ & 38 & 12 & 13 & 9 & 26 & 13 \\
\hline \multicolumn{7}{|l|}{ Jobs } \\
\hline Civil Servant & 36 & 11 & 18 & 15 & 18 & 10 \\
\hline Office Worker & 114 & 34 & 37 & 26 & 78 & 40 \\
\hline Student & 75 & 23 & 30 & 21 & 46 & 24 \\
\hline $\begin{array}{l}\text { Self-Employe } \\
\text { d }\end{array}$ & 62 & 19 & 33 & 23 & 30 & 15 \\
\hline Unemployed & 28 & 9 & 19 & 14 & 10 & 5 \\
\hline Other & 33 & 10 & 12 & 8 & 22 & 12 \\
\hline \multicolumn{7}{|l|}{$\begin{array}{l}\text { Monthly } \\
\text { Income }\end{array}$} \\
\hline$<\$ 2000$ & 87 & 25 & 39 & 27 & 48 & 24 \\
\hline$\$ 2000-\$ 4000$ & 150 & 44 & 61 & 42 & 89 & 45 \\
\hline$\$ 4000-\$ 6000$ & 69 & 20 & 29 & 20 & 40 & 20 \\
\hline$\$ 6000-\$ 8000$ & 16 & 5 & 4 & 3 & 12 & 6 \\
\hline
\end{tabular}




\begin{tabular}{|l|l|l|l|l|l|l|}
\hline$>\$ 8000$ & 20 & 6 & 11 & 8 & 9 & 5 \\
\hline
\end{tabular}

The X2 test was used to ascertain whether there were statistically significant differences in the demographic characteristics of heavy and light users. Along with monthly income, the data suggested that there were significant differences among light and heavy users in case of sex, age, family status, degree, and job.

\subsection{The effect of the e-servicescape on the purchasing intentions of common Internet users}

The purpose of this study is to compare the e-most servicescape's critical components and to throw light on the relationship between the e-servicescape and purchase intention for general, heavy, and light users. To begin, this study investigates the effect of the e-servicescape on the purchasing intentions of everyday Internet users. Visual appeal $(\beta=0.465, \mathrm{p} 0.01)$ and interaction $(\beta=0.320, \mathrm{p} 0.01)$ have a considerable favorable effect on purchase intention, according to data (Figure 2). Neither design nor functionality, on the other hand, had a statistically significant influence on purchase intention $(\beta=0.13, \mathrm{p}>0.1)$. In contrast to expectations, financial stability had a moderately negative but statistically significant effect on purchase intent among general users $(\beta=-0.344, \mathrm{p} 0.1)$. As a result, $\mathrm{H} 1$ is only supported in part.

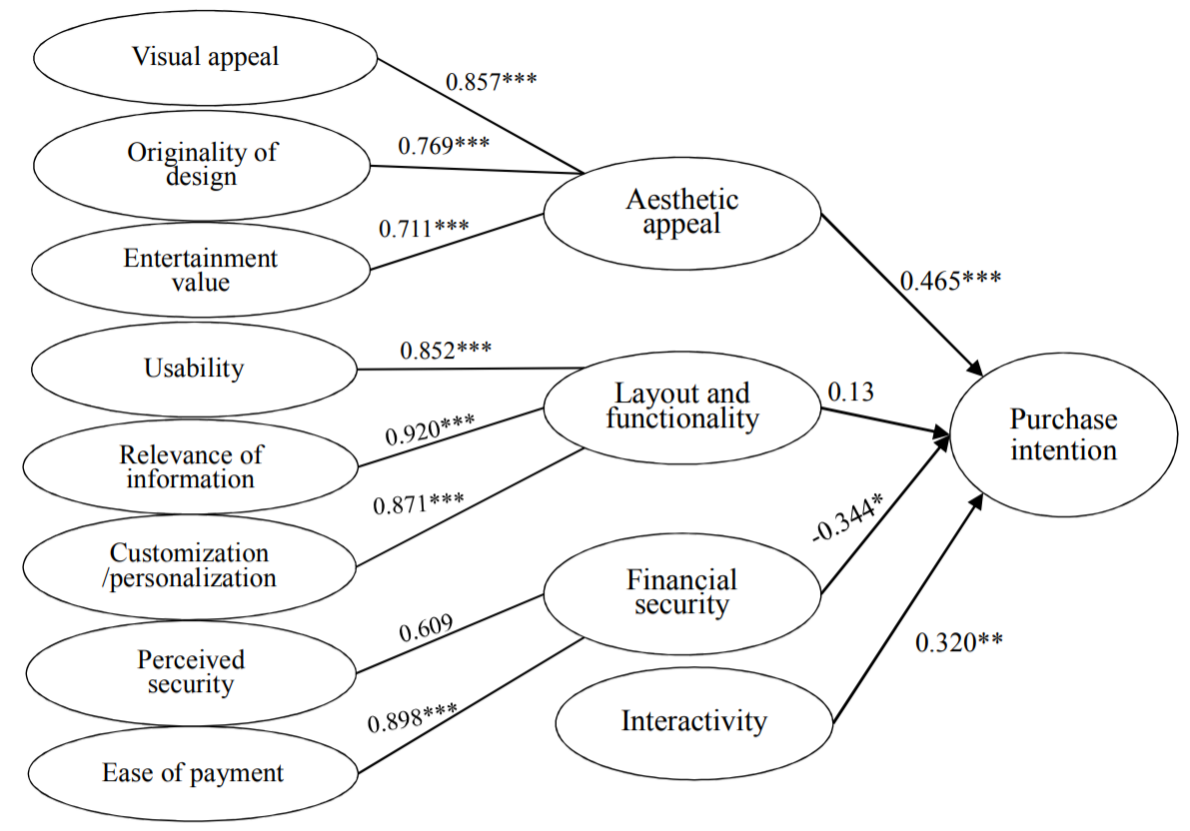

Fig. 2. SEM analysis results for common Internet users

\subsection{The effect of the e-servicescape on purchase intention among frequent and infrequent Internet users}

The figures 3 and 4 illustrate the e-effect servicescape's on the purchasing intents of heavy and light Web users, respectively. To start, we assessed the effect of each aspect on heavy and light users to see whether any statistically major changes occurred. Both for heavy $(\beta=0.462, \mathrm{p} 0.01)$ and light users $(\beta=0.392, \mathrm{p} 0.01)$, aesthetic value significantly improved purchase intention. As a consequence, it is not suggested to use H2-1. Only among heavy users did layout and functionality improve purchase intention considerably $(\beta=0.10, \mathrm{p} 0.1)$. As a consequence, H2-2 is considered to be acceptable. Unlike what we expected, economic sustainability had no effect on purchase intention among heavy $(\beta=-0.061, p>0.1)$ or light $(\beta=-0.076, p>0.1)$ users. As a result, it is not recommended to utilize H2-3. Finally, contact raised purchase intention considerably only for heavy users $(\beta=0.621, \mathrm{p} 0.01)$. As a consequence, $\mathrm{H} 2-4$ is considered to be acceptable. We conclude that $\mathrm{H} 2$ is supported since the layout impacts, functionality, and interaction of heavy and light users are different. 


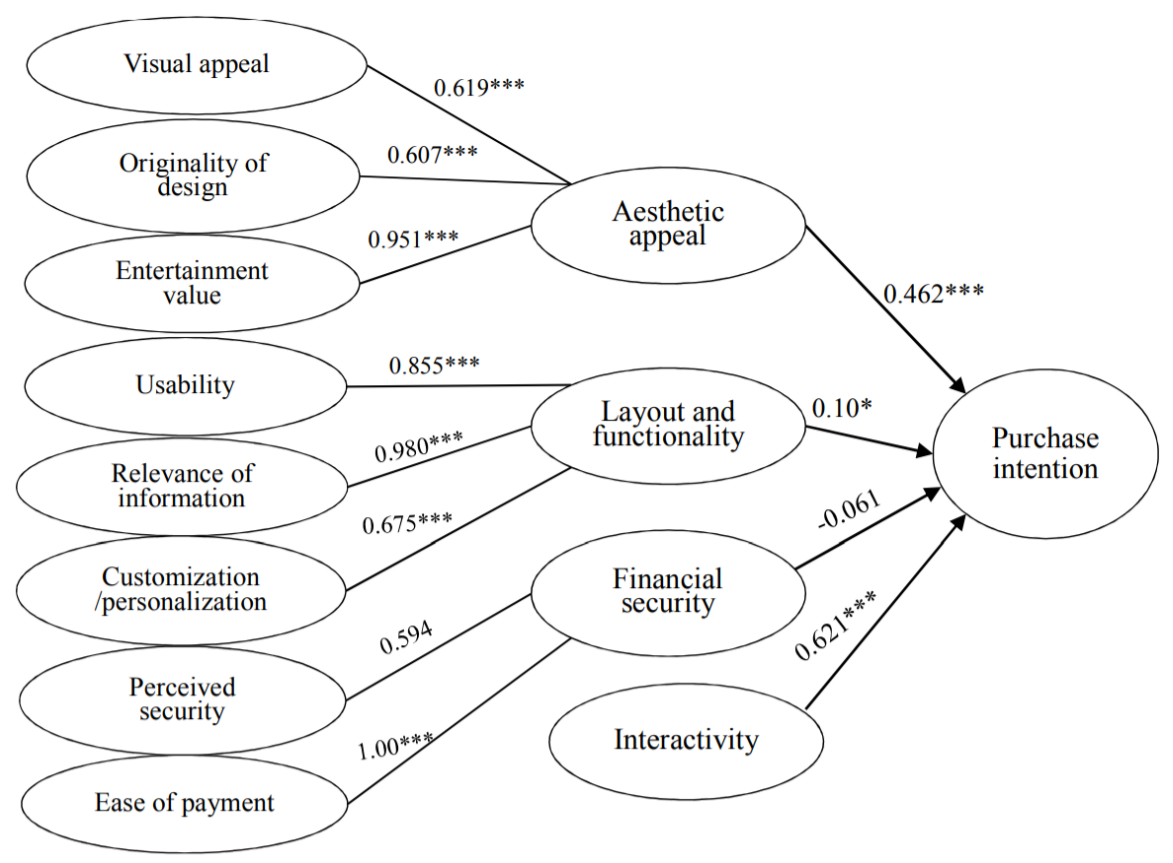

Fig. 3. SEM study results for heavy Internet users

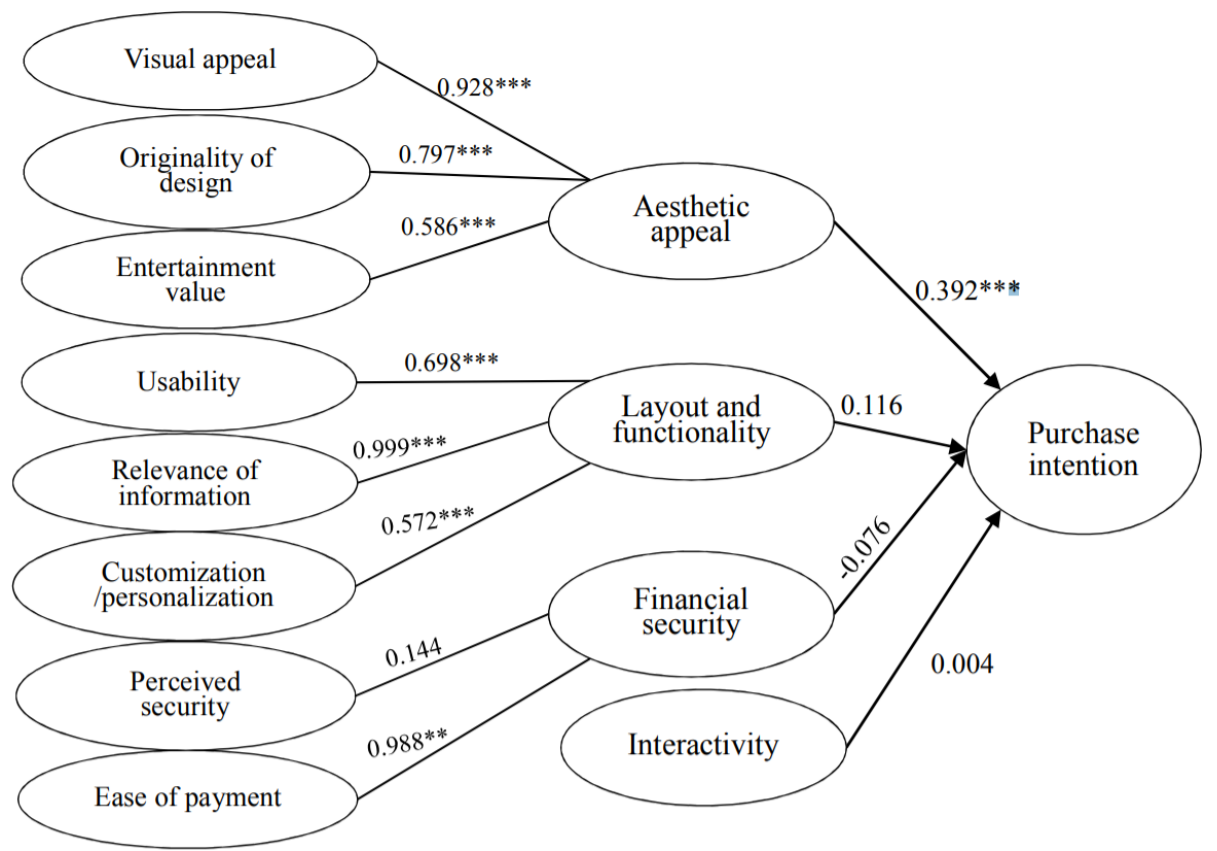

Fig. 4. SEM analysis results for light Internet users

\section{Conclusion}

\subsection{Theoretical implications}

We demonstrate how heavy and light Internet users perceive their e-servicescape features and how different consumption qualities influence their cognitive reactions and buy intentions by integrating e-service quality and segmentation theory into e-servicescapes and purchase intentions [24]. We contribute to the body of knowledge by addressing the following research gaps.

To begin, we react to calls for new dimensions or sub-dimensions of e-servicescapes by introducing interactivity and examining its relationship to purchase intention using a second-order construct. Our empirical research suggests that explaining the subdimensions may help us gain a more complete knowledge of how heavy and light Internet users view various subdimensions of the e-servicescape and which service quality aspects they highlight to boost their 
purchase intention [25]. More precisely, our statistics on financial security indicate that Internet users prioritize "ease of payment" over "perceived security," while our data on style and functioning indicate that "information relevancy" takes precedence over "usability" and "customization."

Second, in response to calls for increased attention to the quality of online services, we incorporate e-service quality and segmentation theory into the e-servicescape model to uncover potential contextual components. (i.e., consumer behavior) to impact the landscape of e-services and purchase intention [26]. According to our empirical findings, both frequent and infrequent Internet users regard e-servicescapes as indications of service quality. Users gain knowledge and expertise regarding special qualities of e-servicescapes as a result of their unique consumption behavior and contribute preferred quality attributes and sequential behavioral goals. More precisely, because heavy users invest significant time and money in online shopping, they view layout and functionality as critical tools for product discovery (that is, ease of use), as they are more knowledgeable and experienced in online shopping environments and seek out more information than light users do [27]. If such an Online store offers higher interactive features such as immediate answers or feedback to serve consumers in resolving their troubles, heavy users will perceive the site's e-servicescapes as needing a higher quality of service (higher quality relevant information) and this will positively influence their buying behaviour patterns.

Thirdly, we examine the frequency with which Internet users access the Internet and their interactions with the online world. We were able to identify the most significant components of e-servicescapes and offer a more precise explanation for how e-servicescapes affect purchase intention by focusing on these consumers (who account for approximately $80 \%$ of online sales) by focusing on them.

Finally, we establish empirical evidence that heavy users prefer "entertainment value," whereas light users favor "visual appeal," by evaluating the subdimensions of the e-servicescape and the differences in the nature of consumption. According to a previous study, heavy users value visual beauty more than light users [28]. As a result, we assert that the visual appeal of a quality as perceived by heavy and light users is quite different. Due to the fact that light users have less expertise and comprehension of online purchasing than heavy users, Internet retailers' purchase intent will improve if they display an aesthetically pleasing website to sustain their interest [29]. Additionally, financial security has no noticeable effect on either frequent or infrequent users. According to a new poll, financial security is critical in the online shopping environment, especially when it comes to online payment operations. In contrast to previous research, this research findings indicate that "ease of payment" may be a critical factor to emphasize, and that differences in the nature of their consumption also influence their perception of e-servicescape attributes, owing to the frequency with which Internet users make online purchases. have sufficient competence and experience with payment security systems, and they may prioritize other features of the e-servicescape above privacy. Similarly, light users place a higher premium on financial security (privacy) than heavy users do [30].

\subsection{Managerial implications}

The outcomes of the study have a variety of consequences for online merchants. Consumers can be classified as heavy or light users according to their purchasing frequency, purchase quantity, and time consumption, and their preferences for e-servicescapes differ greatly. Internet merchants are required to categorize these high users using the criteria outlined above. They should give preference to frequent consumers and keep track of each consumer's online shopping time, interest categories, and purchase history (i.e., quantity and price). They may redesign their present e-servicescapes and use more effective marketing tactics in order to attract high numbers of consumers. For example, it was discovered that heavy users place a higher premium on website credibility, keyword search capabilities, comparability, user-friendliness, ease of search, visual information accessibility, customization, meeting demands, and online Q\&A. If Internet retailers implement this function onto their website, heavy users will discover that it is easier to use and more efficient than others, steadily increasing their buy intention. Additionally, we encourage Internet merchants to promote segmentation; otherwise, heavy consumers may switch to competitors with more profitable goods. 
Additionally, internet merchants might target light consumers and entice them to spend more frequently, perhaps to the point of becoming heavy consumers. Our findings indicate that aesthetic appeal, namely visual appeal, is a necessary condition for light users and that Internet firms may increase light user acquisition by stressing design and aesthetic qualities.

On the basis of our findings about the second-order structure of the e-servicescape, we also recommend that Internet retailers prioritize the automatic delivery of useful information, enforce mutual interaction, alert consumers when desired products are about to sell out, inform consumers about upcoming discounts, and provide bundles tailored to consumer requirements. We think that this method enables more exact customer segmentation and service quality enhancement, hence enhancing consumer behavioral intents and optimizing online merchants' operational performance.

\subsection{Limitations and further research}

Numerous limitations apply to this inquiry. To begin, even when surveys are sent $60 \%$ in print and $40 \%$ online to mitigate nonresponse bias related with online repeated sampling, research bias may persist. Second, the e-servicescape acts as a multiplier for other factors, as Roy et al. [31] hypothesized that the e-e-effects servicescape's are mediated by rigor. In other words, users must "stay" to a website before creating a sense of loyalty and eventually spreading positive word of mouth about the brand. Harris and Goode [2] assert that online trust is critical in mediating the link between the e-servicescape and purchase intent. Both investigations established that a variety of mediators play a critical role in this relationship. Given the study's narrow focus on the core features of heavy users, more research is required to identify additional relevant mediators. This survey makes no mention of the three types of websites or product attributes. Finally, demographic and psychological factors such as gender and personal characteristics may operate as major mediators in the link between the e-servicescape and purchase intention, necessitating more study to ascertain their implications.

\section{References}

[1] M. J. Bitner, "Servicescapes: The Impact of Physical Surroundings on Customers and Employees," J. Mark., vol. 56, no. 2, p. 57, 1992, doi: 10.2307/1252042.

[2] L. C. Harris and M. M. H. Goode, "Online servicescapes, trust, and purchase intentions," J. Serv. Mark., vol. 24, no. 3, pp. 230-243, 2010, doi: 10.1108/08876041011040631.

[3] Y. Chang and J. Wu, "Multichannel integration quality, online perceived value and online purchase intention: A perspective of land-based retailers," Internet Res., vol. 25, no. 5, 2016.

[4] D. W. Twedt, "How Important to Marketing Strategy Is the 'Heavy User’?," J. Mark., vol. 28, no. 1, p. 71, 1964, doi: $10.2307 / 1249232$.

[5] S. Li, "Linking servicescape and customer engagement: An investigation in the hotel context," Int. J. Hosp. Manag., vol. 94 , no. 422, pp. 12-22, 2021, doi: 10.1016/j.ijhm.2021.102880.

[6] X. Xu and D. Gursoy, "STHRSCAPE: Developing and validating a collaborative economy based short-term hospitality rental servicescape scale," Int. J. Hosp. Manag., vol. 94, no. 4, pp. 102-110, 2021, doi: 10.1016/j.jhm.2020.102833.

[7] X. Pu, F. T. S. Chan, and A. Y. L. Chong, "The Influence of Supply Chain Relationships on The Adoption of Open Standards Inter-Organizational Information Systems : A Conceptual Framework,” Int. J. Appl. Inf. Manag., vol. 1, no. 1, pp. 47-54, 2021.

[8] R. Riyanto, "Training Autonomous Vehicles in Carla model using Augmented Random Search Algorithm," J. Appl. Data Sci., vol. 2, no. 2, pp. 27-35, 2021, doi: 10.47738/jads.v2i2.29.

[9] V. A. Zeithaml, A. Parasuraman, and A. Malhotra, "Service quality delivery through web sites: A critical review of extant knowledge," J. Acad. Mark. Sci., vol. 30, no. 4, pp. 362-375, 2002, doi: 10.1177/009207002236911.

[10] J. Baker, "The role of the environment in marketing services: the consumer perspective," role Environ. Mark. Serv. Consum. Perspect., no. 4, pp. 79-89, 1986.

[11] G. A. Tran, D. Strutton, and D. G. Taylor, "Do microblog postings influence consumer perceptions of retailers' e-servicescapes?," Manag. Res. Rev., vol. 35, no. 9, pp. 818-836, 2012, doi: 10.1108/01409171211256217. 
[12]L. W. Lam, K. W. Chan, D. Fong, and F. Lo, "Does the look matter? The impact of casino servicescape on gaming customer satisfaction, intention to revisit, and desire to stay," Int. J. Hosp. Manag., vol. 30, no. 3, pp. 558-567, 2011, doi: 10.1016/j.ijhm.2010.10.003.

[13] K. P. Lai, S. C. Chong, H. Bin Ismail, and D. Y. K. Tong, “An explorative study of shopper-based salient e-servicescape attributes: A Means-End Chain approach,” Int. J. Inf. Manage., vol. 34, no. 4, pp. 517-532, 2014, doi: 10.1016/j.ijinfomgt.2014.01.010.

[14] J. S. Chiou and L. Y. Pan, “Antecedents of Internet retailing loyalty: Differences between heavy versus light shoppers," J. Bus. Psychol., vol. 24, no. 3, pp. 327-339, 2009, doi: 10.1007/s10869-009-9111-7.

[15]B. Figueiredo, H. P. Larsen, and J. Bean, “The Cosmopolitan Servicescape,” J. Retail., vol. 97, no. 2, pp. 267-287, 2021, doi: 10.1016/j.jretai.2020.09.001.

[16] M. Kim, "Conceptualization of e-servicescapes in the fitness applications and wearable devices context: Multi-dimensions, consumer satisfaction, and behavioral intention," J. Retail. Consum. Serv., vol. 61, no. 1, pp. 102-111, 2021, doi: 10.1016/j.jretconser.2021.102562.

[17] Y. Zheng, W. Wei, N. Line, and L. Zhang, "Integrating the tourist gaze with the social servicescape: Implications for creating memorable theme park experiences," Int. J. Hosp. Manag., vol. 93, no. 6, pp. 102-123, 2021, doi: 10.1016/j.ijhm.2020.102782.

[18] N. R. Davis and W. W. Mapleson, “A physiological model for the distribution of injected agents, with special reference to pethidine,” Br. J. Anaesth., vol. 70, no. 3, pp. 248-258, 1993, doi: 10.1093/bja/70.3.248.

[19]P. Korgaonkar and L. D. Wolin, "Web usage, advertising, and shopping: Relationship patterns," COMPEL - Int. J. Comput. Math. Electr. Electron. Eng., vol. 28, no. 2, pp. 191-204, 2009, doi: 10.1108/10662240210422549.

[20]L. P. Pleshko and S. Al-Houti, "Heavy versus light users: A preliminary study of behavior patterns in retail services," Acad. Mark. Stud. J., vol. 16, no. SI, pp. 61-73, 2013.

[21] W. B. Dodds, K. B. Monroe, D. Grewal, B. Dodds, and B. Monroe, "Effect of Price, Brand, and Store Information Buyers' Evaluations," J. Mark. Res., vol. 28, no. 3, pp. 307-319, 1991.

[22] H. H. Chang and S. W. Chen, "The impact of online store environment cues on purchase intention: Trust and perceived risk as a mediator,” Online Inf. Rev., vol. 32, no. 6, pp. 818-841, 2008, doi: 10.1108/14684520810923953.

[23] P. M. Podsakoff and D. W. Organ, "Self-Reports in Organizational Research: Problems and Prospects,” J. Manage., vol. 12, no. 4, pp. 531-544, 1986, doi: 10.1177/014920638601200408.

[24] G. Thelen, "Leadership in a Global World Management Training Requirement Using The Example of The Asian Studies Program at University of Applied Sciences (HTWG) Konstanz," Int. J. Appl. Inf. Manag., vol. 1, no. 3, pp. 125-135, 2021, doi: 10.47738/ijaim.v1i3.14.

[25] S. Taylor, "The socially distant servicescape: An investigation of consumer preference's during the re-opening phase,” Int. J. Hosp. Manag., vol. 91, no. 6, pp. 78-90, 2020, doi: 10.1016/j.ijhm.2020.102692.

[26]X. Y. Mei, E. Aas, and O. Eide, “Applying the servicescape model to understand student experiences of a Norwegian academic library,” Libr. Inf. Sci. Res., vol. 42, no. 4, pp. 101-151, 2020, doi: 10.1016/j.lisr.2020.101051.

[27] J. Yeung, "Data Analytics Architectures for E-Commerce Platforms in Cloud,” Int. J. Appl. Inf. Manag., vol. 1, no. 1, pp. 1-5, 2021, doi: 10.47738/ijaim.v1i1.3.

[28] R. F. Chao, Y. Fu, and C. H. Liang, "Influence of servicescape stimuli on word-of-mouth intentions: An integrated model to indigenous restaurants,” Int. J. Hosp. Manag., vol. 96, no. 4, 2021, doi: 10.1016/j.ijhm.2021.102978.

[29] N. Mohd Nor, W. Steeneveld, M. C. M. Mourits, and H. Hogeveen, "The optimal number of heifer calves to be reared as dairy replacements,” J. Dairy Sci., vol. 98, no. 2, pp. 861-871, 2015, doi: 10.3168/jds.2014-8329.

[30]B. T. Andrés, A. C. Taulet, and H. C. García, "How emotional response mediates servicescape impact on post consumption outcomes: An application to opera events," Tour. Manag. Perspect., vol. 34, no. February, pp. 100-115, 2020, doi: 10.1016/j.tmp.2020.100660.

[31] S. K. Roy, W. M. Lassar, and G. T. Butaney, "The mediating impact of stickiness and loyalty on word-of-mouth promotion of retail websites: A consumer perspective,” Eur. J. Mark., vol. 48, pp. 1828-1849, 2014, doi: 10.1108/EJM-04-2013-0193. 